\title{
Intermediate Fibrohistiocytic Neoplasm
}

National Cancer Institute

\section{Source}

National Cancer Institute. Intermediate Fibrohistiocytic Neoplasm. NCI Thesaurus. Code C6491.

A fibrohistiocytic neoplasm usually affecting younger patients. It is characterized by an increased risk of local recurrence and a low risk of metastasis. 